\title{
The Use of Gestalt Approaches for Understanding Adaptive Behaviors in Channels of Distribution
}

\author{
Brent M. Wren ${ }^{1}$ \\ ${ }^{1}$ College of Business Administration, The University of Alabama in Huntsville, Alabama, USA \\ Correspondence: Brent M. Wren, College of Business Administration, The University of Alabama in Huntsville, \\ Huntsville, AL35899, USA. Tel: 1-256-824-6338. E-mail: wrenb@uah.edu
}

\author{
Received: July 5, $2013 \quad$ Accepted: July 18, $2013 \quad$ Online Published: November 7, 2013 \\ doi:10.5539/ijms.v5n6p1 URL: http://dx.doi.org/10.5539/ijms.v5n6p1
}

\begin{abstract}
Several recent studies have focused on the adaptive response of channel members to internal and external environmental changes. This research has sought to explain and predict the manifestation of particular organizational actions in response to environmental demands. The majority of this research has adopted a contingency-based approach. The present paper argues that the use of a Gestalt approach might provide a more thorough understanding of the phenomena being studied. In supporting this thesis, the author will (a) discuss the major weaknesses of the contingency approach, (b) provide evidence supporting the existence and usefulness of Gestalts, and (c) describe the techniques used in identifying channel gestalts.
\end{abstract}

Keywords: gestalts, adaptive behavior, channels of distribution

\section{Introduction}

A great deal of effort and research in distribution channels has been given to examining how channel organizations deal with various internal and external environments (cf. Achrol \& Stern, 1988; Dwyer \& Oh, 1987; Dwyer \& Welsh, 1985; Heide \& John, 1988, 1990). In this pursuit, many researchers are focusing on how certain variables interact to affect organizational adaptation, a concept known as the contingency approach (cf. Achrol, Reve, \& Stern, 1983; Heide \& John, 1988; Stern \& Reve, 1980).

While the use of contingency theory to explain relationships between environmental, structural, and behavioral (strategic) variables seems useful, there may be problems in the normative and descriptive approaches being adopted in examining such contingent relationships. For example, Heide \& John (1988) tested whether or not the positive effects of replaceability on performance were contingent upon the investment levels of certain assets. This research possibly underidentified the actual nomological network involved because of the exclusion of other relevant organizational characteristics from the study (e.g., relational norms, governance structures, power-dependency). Research in organizations has shown that a multiplicity of variables and relationships need to be examined to appropriately characterize organizational adaptation (e.g., Chandler, 1962; Hedberg, Nystrom, \& Starbuck, 1976). In sum, it seems that the contingency approach has several flaws, one of which is that its approach is too narrow and limited.

If the above statement is true, it seems that the validity and generalizability of contingency approaches in examining adaptive behaviors may be lacking. The present paper will propose a potentially more robust approach to examining behaviors and relationships in distribution channels, namely that of Gestalt theory. Gestalt theory has been developed as a useful approach in the strategic management area over the last decade (cf. Miller \&Friesen, 1980; Miller \& Mintzberg, 1984; Miller, 1981, 1986).

It will be argued that rather than focusing on a constricted set of linear relationships between certain contingency variables, researchers should be seeking to identify "configurations" or adaptive patterns that describe the interaction among thee variables (Miller, 1981). As Miller (1981, p.3) states:

"These configurations or patterns are expected to have tightly interdependent and mutually supportive parts, the significance of which can best be understood by making reference to the whole."

Working from this definition, Miller \& Friesen (1984) propose that when such a configuration is found to be commonly represented among the involved cases, and is "predictively useful", the result is called a Gestalt. The present paper will discuss Gestalt theory as it has been developed in the management literature, as well as its 
potential application in the channels context. In this effort, the author will further discuss weaknesses of the contingency approach and outline the rationale for the use of Gestalt theory in distribution channels. Finally, the author will discuss the process of identifying and applying Gestalts in channels of distribution.

\section{The Contingency Approach}

The basic idea behind contingency theory is that, depending on the situation, certain approaches are better at explaining organizational functioning (e.g., adaptation, survival) than others (Galbraith, 1973). Thus organizational effectiveness becomes dependent upon the appropriate matching of contingency variables (i.e., situational characteristics) with particular internal organizational designs that allow for appropriate responses to the environment (Zeithaml, Varadarajan, \& Zeithaml, 1988).

An example of the application of the use of contingency theory in channels literature is Stern and Reve's (1980) political economy paradigm. In this research, the authors define contingency variables in terms of the observed internal and external political economies which are viewed as contingent upon the context of their interaction. Each of the contingent situations would then require different interorganizational management strategies. Other examples of contingency theories in distribution channels include Frazier and Sheth's (1985) operationalization of their attitude-behavior framework, Heide \& John's (1988) examination of the role of dependence-balancing in transaction-specific asset management, and Achrol et al.'s (1983) assessment of channel environments.

\subsection{Problems with the Contingency Approach}

Though the simplicity of the contingency theory has been proclaimed by prominent researchers such as Zeithaml et al. (1988), its application has been strongly scrutinized by many researchers (cf. Miller, 1981; Miller \&Friesen, 1980, 1984; Schoonhoven, 1981). These authors and others have pointed to a number of weaknesses in the underlying assumptions of contingency theory which often lead to fragmented and conflicting findings. One of the most frequently mentioned weaknesses of contingency theory is that it searches for "the one correct path" for dealing with an occurrence (Miller, 1981). In reality, there are actually several equally viable paths from which to choose in the same environment. When one adopts the orientation of contingency theory, they often are not open to finding all possible models for adaptation in a given environment, thus resulting in a narrow approach to the solution.

A second weakness of the contingency approach is the general reliance on linear models and correlation methods to assess relationships between variables (Schoonhoven, 1981). In assuming a linear relationship, the researcher may in fact be masking nonlinear, moderating relationships between the contingency variables and the response measure. This often leads the researcher to assume that the same relationship between variables will hold in different contexts (See Miller \&Friesen, 1980 for detailed discussion). A related weakness is that measures are generally cross-sectional in nature, which limits the generalizability of many findings. This is one source of conflicts over findings, as several researchers may study similar situations and arrive at different conclusions. Given this impairment it would be difficult to make any substantive progress in a discipline.

A fourth weakness of contingency theory is that researchers often fail to address the interaction between contingency variables. For example, Achrol et al., (1983) stated that there was a relationship between particular environmental uncertainties and the resulting coping skills utilized by a firm which predicts the dyadic power balance. Thus, the researchers actually implied that there was an interaction between the two contingent variables. However, no interactive component was explicitly established, therefore the accuracy of the contingency relationship must be questioned.

A final weakness of contingency theory is that the approach limits the researcher's ability to develop parsimonious descriptions of complex contingency relationships the involved variables (Miller, 1981). The contingency approach tends to concentrate on a limited number of variables, testing for simple relationships. In so doing, the researcher may miss underlying patterns or holistic interpretations of reality (Miller \& Friesen, 1984). In other words, many potentially intervening variables may be ignored. The overly restrictive nature of contingency theory potentially conceals much of the complexity of distribution channels. We need to be able to consider the multiplicity of environmental, structural, and behavioral attributes that will interact to influence organizational responses.

\section{The Gestalt Approach}

The gestalt approach was introduced in the strategic management literature by Miller \& Friesen (cf. Miller, 1981; Miller \& Friesen, 1980, 1984). This approach provides a method by which researchers can dissect the complexity of relationships between environment, structure, and behavioral antecedents to interorganizational adaptation. In a sense, this approach is holistic, in that it attempts to assess the influence of a large number of variables that "collectively define a meaningful and coherent slice of organizational reality" (Miller, 1981, p.8).

The goal of the researcher is to use taxonomic procedures (cf. Hall, Haas, \& Johnson, 1967; McKelvey, 1975; Pinto 
\& Pinder, 1972; Pugh, Hickson, \& Hinnings, 1969; Samuel \& Mannheim, 1970) to box or cluster given sets of organizational factors so as to provide a means of identifying remaining features. These natural clusters or "configurations" of variables (i.e., environmental, structural, and/or behavioral dimensions) are then tested for predictive utility. Predictive utility is assessed based on the ability of the configuration to take a partial description of an organizational form and identify its Gestalt, thus allowing prediction of its remaining features (Miller, 1986). When these configurations are predictively useful they are referred to as Gestalts.

Miller \& Friesen (1984) outline four characteristics of Gestalts: 1) a large number of qualities (e.g., states, processes, and situations) are studied in order to yield a detailed, holistic, integrated image of reality; 2) data analysis and theory building are geared to finding common natural clusters among the attributes studied; 3) causation is viewed in the broadest possible terms; and 4) time and process are taken into account whenever possible (favors longitudinal research).

In using a Gestalt approach researchers are attempting to construct an organizational taxonomy that discriminates among different configurations of variables (i.e., different organizations) so that the subsequent organizational form might be predicted and further evaluated (Miller \& Friesen, 1984). These authors further note that "such a taxonomy will be of value only if it is likely to classify a randomly selected organization from the population using a small number of variables, and to predict accurately many of its other attributes or relationships simply by making reference to its class membership (Gestalt)."

Several examples of predictive Gestalts can be found in the management strategy literature, where configurations have been derived in areas such as, structural, environmental, and strategy/behavioral attributes. This research includes derived Gestalts developed by Chenhall (1983), Dess \& Davis (1984), Galbraith \& Schendel (1982), Hambrick (1983), Hambrick \& Schecter (1983), Lawrence \& Lorsch (1967), Miles \& Snow (1978), and Mintzberg (1979).

\subsection{Evidence for Gestalts}

Miller \& Friesen (1984) provide three arguments which evidence the existence of organizational Gestalts. First, is the Darwinistic argument that "only a limited number of richly descriptive and common organizational forms survive in the same setting." According to Hannan \& Freeman (1977) formal organizations are subject to selection processes quite similar to those faced by biological species. This would imply that only a finite number of adaptive patterns will emerge from the search for Gestalts. The presence of a limited number of effective and efficient configurations will enhance their usefulness.

The second argument for the existence of Gestalts is that organizations are driven towards a common configuration in order to achieve internal harmony among its elements of strategy, structure, and context (Miller, 1986). In other words, certain attributes tend to be complementary and mutually reinforcing, thus forcing an alignment of commonalities in the organization. For example, in environments characterized by high degrees of change, where product innovation is constantly required, successful firms will tend to exhibit less routinization and standardization, decentralized decision-making, and fewer controls. This situation would tend to push firms toward a dynamic environment where R\&D could be exploited. This type of scenario is common in many different settings and aids in the search for Gestalts.

The final argument for Gestalts is that organizations tend to avoid making frequent changes in operation (Miller, 1986). While the contingency approach advocates making frequent changes to accommodate changes in environment, this is an unrealistic expectation of organizations, due in part to the costs and risks involved. More typically, organizations adapt a quantum change approach with long periods of maintenance of a given configuration, followed by brief, sweeping transitions. This strategy favors a Gestalt approach, due to the degree of internal consistency involved.

\subsection{Potential for Gestalts in Distribution Channels}

The preceding section presented reasons why one would expect to find regularities in the actions of simple organizations. Based on the literature suggesting similarities between simple and complex organizations (Stern \& El-Ansary, 1988), one would logically assume that potential exists for predictively useful configuration or Gestalts that describe behaviors in channel organizations. Similar to simple organizations, in channel organizations the environment will restrict the number of possible strategies and structures available in that environment. Further, there will be ties that unite certain channel structures and behavioral repertoire. In other words, given a particular structure, there will be only a limited number of suitable behavioral/strategy alternatives which lead to desirable outcomes. Finally, channel organizations have been shown to exhibit relatively stable attributes (Stern \& Reve, 1980), which leads to the expectation of somewhat stable patterns of organizational functioning. Given these observations it is 
logical to extend the Gestalt approach, as utilized in other settings, to the channel environment.

\section{Methods for Identification of Gestalts}

The goal of defining predictive configurations or Gestalts is to derive a parsimonious set of categories encompassing a large proportion of the population of organizations and to develop a taxonomy of configurations that are sufficiently restrictive (i.e., tightly defined) to allow meaningful descriptions of their members (McKelvey, 1975). Thus, a parsimonious taxonomy with high predictive ability will be needed to validate the superiority of Gestalt approach over the contingency-based approach.

McKelvey (1975) distinguishes between two types of configurations: taxonomies and typologies. Taxonomies are empirically driven approaches which start with broad, representative random samples and use multivariate analysis techniques such as cluster analysis, hierarchical clustering, factor analysis, and/or multidimensional scaling, to generate configurations (See Miller \& Friesen, 1984). Typologies, on the other hand, are conceptual configurations which are developed intuitively on the basis of their detailed descriptions. Once this has been done across a number of categories or types of channels, the descriptions can be used to build a parsimonious set of predictive typologies.

Most researchers seeking to develop Gestalts will use a combination of these two approaches so as to ensure both the theoretical foundation, and the empirical stability of the clusters. McKelvey (1975) recommends several useful guidelines for the development of configurations. Following these guidelines should help to produce a parsimonious and robust set of configurations. The major points are as follows:

1) Define the broadest possible population of organizations or, if delimitation is unavoidable, base it on a significant cultural unit. This argument says that one should try to represent as many types of organizations as possible.

2) Use a probability sampling plan without any stratification for selecting a sample of organizations. This assures that all members of the population have equal likelihood of being selected. By avoiding stratification, one avoids making assumptions about which attributes are more important than others in classification.

3) Define as inclusive a population of organizational attributes as possible. To avoid overlooking potential classificatory attributes, one must include all known organizational attributes of the collective members or subunits.

4) When necessary, use a probability sampling plan for selecting a sample of organizational attributes.

5) Define the population of observers of organizational attributes to be as inclusive as possible. When necessary, use a stratified probability sampling plan for selecting observers. This will incorporate the input of informants at all levels of the organization, rather than those of a single level, such as top management.

6) All criteria utilized in making unavoidable assumptions and decisions must be publicly described and consistently applied, so as to aid in subsequent tests and replications.

\subsection{Taxonomic Methods}

When one decides to employ the taxonomic (empirically-driven) approach to discover configurations, there are two general types of grouping procedures. One technique, the Q-approach, involves seeking relationships among cases; the other technique, the R-approach, seeks relationships among variables (Miller \& Friesen, 1984). Miller and Friesen recommend using Q-type procedures due to their ability to accommodate nonlinear relationships among the cases which make up a cluster. The Q-type procedure is more parsimonious and leads to denser clusters of firms. With the Q-approach, one uses various multivariate grouping techniques to cluster the cases in a study, then tries to discover what characteristics are associated with each cluster. In other words, we attempt to determine the degree of association between the cases in a given cluster based on the attributes which are defined in the study.

The techniques which accommodate Q-type grouping procedures include mathematical algorithms, cluster analysis, hierarchical clustering, factor analysis, and multidimensional scaling (For detailed discussion of these methods, see Miller \& Friesen, 1984; Hair et al., 1979). It is important to note that, although the goal of each technique is the same (i.e., producing clusters which are maximally similar within groups with minimal similarity between groups), the various methods will potentially yield different groupings. Thus, it is useful to try several different multivariate techniques in order to determine which groupings are most revealing (Miller \&Friesen, 1984). In the end, those groupings that most enhance the understanding and predictive utility of the configurations should be utilized.

\subsection{Applying the Gestalt Approach in Distribution Channels}

To illustrate the application of the gestalt approach to distribution channels, the author will work through the guidelines provided by McKelvey (1975) identified earlier. The initial step would be to identify the population of organizations to be used in the analysis. To accomplish this one would select a population of channel organizations 
which is relevant to the phenomena being studied. Definition of the population is generally closely related to defining the phenomena to be studied. The idea is to define the population from which the necessary information can be gleaned. For example, if one wants to study the relationship between franchisees and the franchisers, the population would include as many different types of franchises as possible, so as to avoid the degenerative effects of focusing on a single channel structure.

Once the population has been defined, the next step would be to select the organizations which will be selected from the population. As McKelvey (1975) recommends, this should be performed on a probability basis so as to represent the full range of involved organizations. For example, in the above situation, one would select a sample of organizations from the population so that each type organization found in the population is represented.

In the selection of organizational attributes to be included, the relevant attributes or variables for characterizing the primary contingency dimensions in the channel analysis would include structure, environment, and/or behavior considerations. In selecting structure elements, one would want to include variables that are sufficiently specific to be both identifiable and controllable by channel leaders, and general enough to be applied across channel contexts. Collectively, these variables would need to cover the specific elements that characterize the structuring of the distribution channel. This list would include such variables as power-dependency, centralization, bureaucratization (i.e., controls, formalization, centralization), functional specifications, information systems, coordinative systems, and bilateral governance structures.

In dimensionalizing the channel environment, one could draw upon the works of Achrol et al., (1983), Achrol \& Stern (1988), Brown \& Nicholson (1990), Dwyer \& Oh (1987), and/or Dwyer \&Welsh (1985). Peripheral elements would include dynamism (i.e., uncertainty), concentration, capacity, diversity, and interconnectedness. One would also include characteristics of the external environment such as competitiveness, regulation, and trade associations.

Drawing from the extensive literature on behavioral strategies in channels, potential strategic elements such as asset management (e.g., transaction-specific investments, dependence balancing), power and exercision, influence/communication, conflict resolution (e.g., problem-solving), leadership, and resource allocation would need to be considered. The goal would be to include an exhaustive set of behavioral attributes that adequately describe the range of potential strategic behaviors exercised by channel leaders.

Finally, the observers of these organizational attributes would need to be identified. One would want to incorporate input of informants at all levels of the organizations being studied. For example, in the franchisee situation, informants would range from top management of the franchising organizations to the owner of the franchise to workers at the franchise. By doing this, the information gathered will be more truly representative of the relationship being studied and will avoid the potential bias which is likely if a single group of informants is considered.

Having identified all aspect of the study, the next step would be to collect the information, and then perform the appropriate analyses to identify the existing clusters. It is important to note that using longitudinal data collection procedure will enhance the quality of the Gestalt developed. The utilization of longitudinal studies is uncommon, to say the least. However, if cross-sectional data is used to develop Gestalts, without any time and process considerations, this approach will be subject to many of the same weaknesses as the contingency-based approaches. At the very least, Gestalts should be tested via test-retest or split-halves procedures; however, longitudinal procedures should be utilized whenever feasible.

\section{Conclusions}

As noted earlier, channel researchers are beginning to address the contingent relationships between environment, strategy (behavior), and structure. Initial efforts have focused on contingency-based applications, which may present problems in terms of external validity due to limitations in the application. This paper has proposed that there is potential for a Gestalt-based approach to develop richer interpretations of organizational functioning in distribution channel systems. It is felt that predictive taxonomies can be developed which provide a more parsimonious representation of the adaptive process in distribution channels than is presently being derived in the application of contingency theories.

Future research needs to focus on applying the ideas presented here in order to test whether or not the Gestalt approach can yield improvements over contingency approaches in the channel environment. By following the guidelines presented, channel researchers should be able to identify a practical set of Gestalts within the channel context. If no predictively useful configurations are generated, perhaps improvements in the theoretical principles of Gestalt applications can be achieved. Advancements in the understanding of Gestalt theory will be made by continuous application attempts and subsequent adjustments of the underlying concepts. 


\section{References}

Achrol, R. S., \& Stern, L. W. (1988). Environmental Determinants of Decision Making Uncertainty in Marketing Channels. Journal of Marketing Research, 25(February), 36-50. http://dx.doi.org/10.2307\%2F3172923

Achrol, R. S., Reve, T., \& Stern, L. W. (1983). The Environment of Marketing Channel Dyads: A Framework for Comparative Analysis. Journal of Marketing, 47(Fall), 55-67. http://dx.doi.org/10.2307\%2F1251399

Brown, J. R., \& Nicholson, C.Y. (1990). Governance Structures in a Franchised Channel of Distribution. In Robert A. Robicheau (Ed.), Franchising: Evolution in the Midst of Change. Lincoln, NB: International Center for Franchise Studies, University of Nebraska.

Chandler, A. D. (1962). Strategy and Structure. Cambridge, MA: MIT Press.

Chenhall, R. (1983). Diversification within Australian Manufacturing Enterprises. Journal of Management Studies, 21(1), 23-60. http://dx.doi.org/10.1111/j.1467-6486.1984.tb00223.x

Dess, G., \& Davis, P. S. (1984). Porter's Generic Strategies as Determinants of Strategic Group Membership and Organizational Performance. Academy of Management Journal, 27(September), 467-488. http://dx.doi.org/10.2307\%2F 256040

Dwyer, R. F., \& Oh, S. (1987). Output Sector Munificence Effects on the Internal Political Economy of Marketing Channels. Journal of Marketing Research, 24(November), 347-358. http://dx.doi.org/10.2307\%2F3151382

Dwyer, R. F., \& Welsh, A. M. (1985). Environmental Relationship of the Internal Political Economy of Marketing Channels.Journal of Marketing Research, 22(November), 397-414. http://dx.doi.org/10.2307\%2F3151585

Frazier, G. L., \& Sheth, J. N. (1985). An Attitude-Behavior Framework for Distribution Channel Management. Journal of Marketing, 49(Summer), 38-48. http://dx.doi.org/10.2307\%2F1251614

Galbraith, J. R. (1973). Designing Complex Organizations. Reading, MA: Addison-Wesley.

Galbraith, J., \& Schendel, D. (1982). An Empirical Analysis of Strategy Types. Working Paper, Purdue University.

Hair, J. F. Jr., Anderson, R. E., Tatham, R. L., \& Grablowsky, B. J. (1979). Multivariate Data Analysis. Tulsa, OK: Petroleum Publishing Company.

Hall, R. H., Haas, J. E., \& Johnson, N. J. (1967). An Examination of the Blau-Scott and Etzioni Typologies. Administrative Science Quarterly, 12(1), 118-139.

Hambrick, D. (1983). An Empirical Typology of Mature Industrial-Product Environment. Academy of Management Journal, 26(1), 213-230. http://dx.doi.org/10.2307\%2F255971

Hambrick, D. C., \& Schecter, S. (1983). Turnaround Strategies for Mature Industrial-Product Business Units. Academy of Management Journal, 26(2), 231-248. http://dx.doi.org/10.2307\%2F255972

Hannan, M., \& Freeman, J. (1977). The Population Ecology of Organizations. American Journal of Sociology, 83, 929-964. http://dx.doi.org/10.1086\%2F226424

Heide, J. B., \& John, G. (1988). The Role of Dependence Balancing in Safeguarding Transaction-Specific Assets in Conventional Channels. Journal of Marketing, 52(January), 20-35. http://dx.doi.org/10.2307\%2F1251683

Heide, J. B., \& John, G. (1990). Alliances in Industrial Purchasing: The Determinants of Joint Action in Buyer-Seller Relationships. Journal of Marketing Research, 27(February), 24-26. http://dx.doi.org/10.2307\%2F3172548

Hendberg, B., Nystrom, P., \& Starbuck, W. (1976). Camping on See-saws: Prescriptions for a Self-Designing Organization. Administrative Science Quarterly, 21(1), 41-65.

Lawrence, P. R., \& Lorsch, J. W. (1967). Organization and Environment. Boston: Harvard University Press.

McKelvey, B. (1975). Guidelines for the Empirical Classification of Organizations. Administrative Science Quarterly, 20(4), 509-525.

Miles, R., \& Snow, C. (1978). Organizational Strategy, Structure, and Process. New York: McGraw-Hill.

Miller, D. (1981). Towards a New Contingency Approach: The Search for Organizational Gestalts. Journal of Management Studies, 18(1), 1-26. http://dx.doi.org/10.1111\%2Fj.1467-6486.1981.tb00088.x

Miller, D. (1986). Configurations of Strategy and Structure: Towards a Synthesis. Strategic Management Journal, 7 , 233-249. http://dx.doi.org/10.1002\%2Fsmj.4250070305

Miller, D., \& Friesen, P. H. (1980). Archetypes of Organizational Transaction. Administrative Science Quarterly, 25, 268-299. 
Miller, D., \& Friesen, P. H. (1984). Organizations: A Quantum View. Englewood Cliffs, NJ: Prentice-Hall.

Miller, D., \& Mintzberg, H. (1984). The Case for Configuration. In D. Miller \& P. H. Friesen (Eds.), Organizations: A Quantum View. Englewood Cliffs, NJ: Prentice-Hall.

Mintzberg, H. (1979). The Structuring of Organizations. Englewood Cliffs, NJ: Prentice-Hall.

Pinto, P., \& Pinder, P. (1972). A Cluster-Analytic Technique to the Study of Organizations. Organizational Behavior and Human Performance, 8, 408-422.

Pugh, D. S., Hickson, D. J., \& Hinnings, C. R. (1969). An Empirical Taxonomy of Work Organizations, Administrative Science Quarterly, 14(1), 115-126.

Samuel, Y., \& Mannheim, B. (1970). A Multi-Dimensional Approach toward A Typology of Bureaucracy. Administrative Science Quarterly, 15(2), 216-228.

Schoonhoven, C. B. (1981). Problems with Contingency Theory: Testing Assumptions Hidden Within the Language of Contingency Theory. Administrative Science Quarterly, 26, 349-377.

Stern, L. W., \& El-Ansary, A. I. (1988). Marketing Channels (3rd. ed.). Englewood Cliffs, NJ: Prentice Hall.

Stern, L. W., \& Reve, T. (1980). Distribution Channels as Political Economies: A Framework for Comparative Analysis. Journal of Marketing, 44(Summer), 52-64. http://dx.doi.org/10.2307\%2F1251111

Zeithaml, V. A., Varadarajan, R., \& Zeithaml, C. P. (1988). The Contingency Approach: Its Foundations and Relevance to Theory Building and Research in Marketing. European Journal of Marketing, 22(7), 37-64. http://dx.doi.org/10.1108\%2FEUM0000000005291

\section{Copyrights}

Copyright for this article is retained by the author(s), with first publication rights granted to the journal.

This is an open-access article distributed under the terms and conditions of the Creative Commons Attribution license (http://creativecommons.org/licenses/by/3.0/). 